\title{
ELECTROSTATIC SEPARATION OF THE SHREDDED PLASTIC MIXTURES USING A TRIBO-CYCLONE*
}

\author{
G. DODBIBA ${ }^{\dagger}$, A. SHIBAYAMA, \\ T. MIYAZAKI and T. FUJITA \\ Satellite Venture Business Laboratory, Faculty of Engineering and \\ Resources Sciences, Akita University, Akita 010-8502, Japan
}

(Received 13 July 2001; Accepted 25 July 2001; In final form 26 July 2001)

In this experimental work, artificial plastic mixture of two kinds of components (i.e. PET and PE mixture) is tribo-electrostatically separated. The mixture is charged by friction in a tribo-cyclone.

After a certain residence time inside the tribo-cyclone, the charged plastic flakes fall down freely through a horizontal electric field into collection bins. The DC electric field of up to $333 \mathrm{kV} / \mathrm{m}$ is created by using two plate electrodes made of $\mathrm{Cu}$ and having a given cross-section configuration. The plastic flakes of the mixture are drawn to either positive or negative electrode according to the polarity of the charge and are separated by falling into different bins. In order to ensure an easy and efficient separation, the inner wall of the tribo-cyclone is made of a suitable plastic material to improve the frictional charging of the flakes. Each plastic component is separated with a grade higher than $95 \%$ and recovery higher than $75 \%$.

Keywords: Plastic separation; Cyclone; Tribo-electric charge; Electrostatic separation; DC electric field

*Presented at MEGS '01 Conference, Falmouth, England, June 2001.

${ }^{\dagger}$ Corresponding author. E-mail: g_dodbiba@lfp03.mine.akita-u.ac.jp 


\section{INTRODUCTION}

Plastics are excellent and very useful materials to replace wood, metals, etc. however, wastes of plastics are difficult to dispose and most of them are used for landfill [1]. Therefore, one of the weakest points in the recycling system is the reuse of waste plastics. Waste plastics amounted to more than 6 million tons and $1.6 \%$ of Japanese industrial waste in 1996 . Only about $36 \%$ of these plastics were reused, a very low percentage when compared to the recovery percentages for metal, glass and waste paper [2].

There are many kinds of plastics in wide use today including polyethylene (PE), polystyrene (PS), polypropylene (PP), and polyvinyl chloride (PVC). Another common example is the polyethylene terephthalate (PET) used in the production of soft-drink bottles. PET is a useful plastic that can easily be reused as raw material for other PET products. As the raw mixture usually includes many other types of plastics, most notably the PE of the bottle caps, this makes the separation of the plastics an important process.

Recently, plastics recycling technology has made good progress in developing different separation methods. The flotation [3-7], and sink-float $[8,9]$ separation techniques are well known wet methods for plastic separation. Otherwise, electrostatic separation, which has been mainly developed for the mineral beneficiation [10-16], has been successfully applied to separate paper from plastic, particularly PVC [17]. In 1995, Arai et al. used a column-type air separator in the dry separation of other plastics from PVC containing chlorine that damages incineration furnace [18]. Moreover, many kinds of plastics have been electrostatically separated by using friction mixer with rotary blades [19], fluidized-bed tribo-electrification [20], or by using a vibrating feeder and electrostatic high voltage generator [21], etc.

Generally, an electrostatic separator consists of feeding, charging and sorting zones. Higashiyama et al. [22] summarized some examples of the application of the electrostatic separators, classified with respect to the charging methods and equipments (Table I).

The aim of the research presented in this paper was to find a suitable dry process that can obtain a high PET-grade when separating PET from PET/PE mixtures. Consequently, we have also developed a laboratory-scale separator employing a tribo-cyclone. 
TABLE I The application of electrostatic separation

\begin{tabular}{ll}
\hline Charging Method & Charging Equipment \\
\hline Induction & Rotational Drum \\
& Slide plate \\
Moving belt \\
Corona & Rotational drum \\
& Moving belt \\
Tribo-electricity & Cylindrical electrode \\
& Cyclone \\
& Rotating cone \\
& Charging tube \\
& Fluidized bed \\
& Electrostatic sieve \\
& Crusher \\
& Rotating pipe \\
& Vibrating feeder \\
& Unknown \\
\hline
\end{tabular}

\section{THE PRINCIPLES OF THE TRIBO-ELECTROSTATIC SEPARATION}

The principle of the tribo-electrostatic separation involves [23]:

1. Triboelectric charging of the shredded plastic flakes of a mixture.

2. Conveying the electrified mixture through an electrostatic field, which separates individual particles according to the magnitude and polarity of the electric charges, acquired during the triboelectrification process.

Therefore, in any tribo-electrostatic separation, it is necessary to have a process by which the individual flakes are frictionally charged and a source of electrical potential to generate the electric field between the electrodes.

\subsection{The Principles of the Tribo-electric Charging}

A basis for the electrostatic separation of a binary mixture can be created if constituents of a mixture acquire charges of opposite polarities. The measure of the polarity is the tribo-electric charging sequence. One of the reported tribo-electric charging sequences is $[9,17]$ :

(positive end) ABS-PP-PC-PET-PS-PE-PVC-PTFE (negative end) 
where ABS denotes acrylonitrile-butadiene-styrene, PP polypropylene, PC polycarbonate, and PTFE polytetrafluoroethylene.

When two plastics in this sequence are rubbed against each other, the plastics on the left-hand-side is charged negatively and the one on the right-hand-side is charged positively. For instance, when PE is rubbed against PS, PE is charged negatively and PS positively. Whereas, when PET is rubbed against PS, PET is charged positively and PS negatively.

In addition, the tribo-electrification phenomena stipulate that when two materials come into contact, an exchange of electric charges can be observed through the contact area [24-27]. Moreover, it is reported that an electron charge transfer takes place from the surface with a smaller work function to a surface with a greater work function [28]. Therefore, the work function of the contact material is a key factor in tribo-electrification. Hence, for tribo-electrification of a binary mixture it will be preferable to use, for contact material, a material with the work function value between the values of the work functions of the two materials in the mixture to be separated $[29,30]$. Some authors have published the work function of plastics $[28,31]$. Table II tabulates some work function values published by those authors.

\subsection{The Principles of the Electrostatic Separation}

Let us consider a spherical flake of charge $Q$ and mass $m$ falling as a result of the gravity between vertical-plate electrodes separated by a distance $d$ and a potential difference of $V$ volts between them (Fig. 1).

The flake will be deflected towards an electrode if the electrostatic force, $F$, acting on it will be greater than the gravitational force, $W$ :

$$
F>W
$$

The gravitational force on the flake is

$$
W=m \cdot g \quad[\mathrm{~N}]
$$

and, the electrostatic force on the flake is

$$
F=Q \cdot E \quad[\mathrm{~N}]
$$


TABLE II The estimated average work function

\begin{tabular}{lc}
\hline Material & Work Function $[\mathrm{eV}]$ \\
\hline PE & $5.24 \pm 0.24$ \\
PS & $4.77 \pm 0.20$ \\
Acrylic & $4.30 \pm 0.29$ \\
PET & $4.25 \pm 0.10$ \\
\hline
\end{tabular}

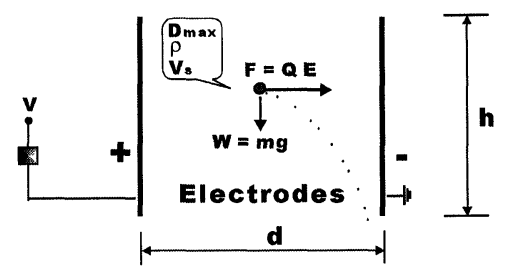

FIGURE 1 Forces acting on particle falling in a transverse electric field.

Hence, relation (1) becomes

$$
Q \cdot E>m \cdot g
$$

In the case of a uniform electric field, the electric field strength $E$ is

$$
E=\frac{V}{d} \quad[\mathrm{~V} / \mathrm{m}]
$$

and the amount of charge acquired by the flake is given by the following formula

$$
Q=4 \varepsilon_{0} \varepsilon_{r} \pi r V_{s} \quad[\mathrm{C}]
$$

where $V_{s}$ is the surface potential measured by a non-contacting type electrostatic voltmeter (i.e. potential difference between the plastic flake and electrostatic voltmeter), while $r$ is the distance between the plastic flakes and the instrument (Fig. 2).

On the other hand, the mass of a spherical flake is

$$
m=\rho \cdot \frac{\pi}{6}(D)^{3} \quad[\mathrm{~kg}]
$$

With the expression for $E$, $Q$ and $m$ given by Eqs. (5), (6) and (7), respectively, the relation (4) becomes

$$
V>\left(\frac{g}{24 \varepsilon_{o} \varepsilon_{r}}\right)\left(\frac{\rho D^{3} d}{r V_{s}}\right) \quad[\mathrm{V}]
$$




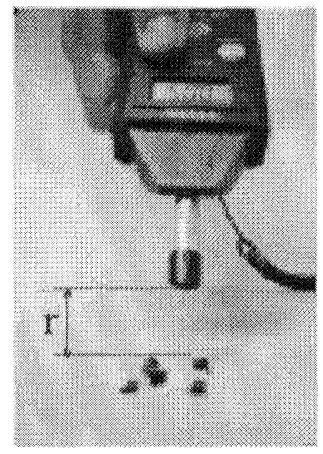

FIGURE 2 The non-contacting type electrostatic voltmeter.

Knowing that

accelaration due to gravity is: $\quad g=9.81 \quad\left[\mathrm{~m} / \mathrm{s}^{2}\right]$

permittivity of free space is: $\quad \varepsilon_{o}=8.854 \times 10^{-12} \quad\left[\mathrm{C}^{2} / \mathrm{Nm}^{2}\right]$

dielectric constant or

permittivity ratio of the air is: $\varepsilon_{r}=1.0059$

the voltage that should be applied to the electrodes, given by Eq. (8), becomes

$$
V>4.59 \times 10^{10}\left(\frac{\rho D^{3} d}{r V_{s}}\right) \quad[\mathrm{V}]
$$

In a generalised form the Eq. (9) is expressed as

$$
E>k \cdot 4.59 \times 10^{10}\left(\frac{\rho D_{\max }^{3}}{r V_{s}}\right) \quad[\mathrm{V}]
$$

where $D_{\max }$ is the maximum diameter of the plastic flake that will be processed, whereas the coefficient $k$, found experimentally, is dimensionless and ranges between 1 and 1.8. It represents the error made during the measurements of the surface potential and, also, takes into account the assumption that the plastic flake had spherical shape.

Hence, it is found that the electric field strength to the electrodes $E$ is a function of the surface potential of the plastic flake $V_{s}$, its size $D_{\max }$ and density $\rho$. In other words, the trajectories of the plastic 
flakes under the influence of the electric field depend on their surface potential level, polarity and size. Moreover, the minimum magnitude of the surface potential $V_{s}$ that a plastic flake must acquire in order to be electrostatically deflected by the given electric filed strength $E$, is calculated by using Eq. (10).

\section{EXPERIMENTAL}

\subsection{An Apparatus and Procedure}

In this experimental work tribo-electrostatic system for separation of shredded plastic mixtures, which employed a tribo-cyclone, is presented.

The schematic design of the laboratory-scale tribo-electrostatic separation system, which is installed inside a temperature and humidity control chamber (ESPEC type TBL-3HAOGAC), is shown in Fig. 3.

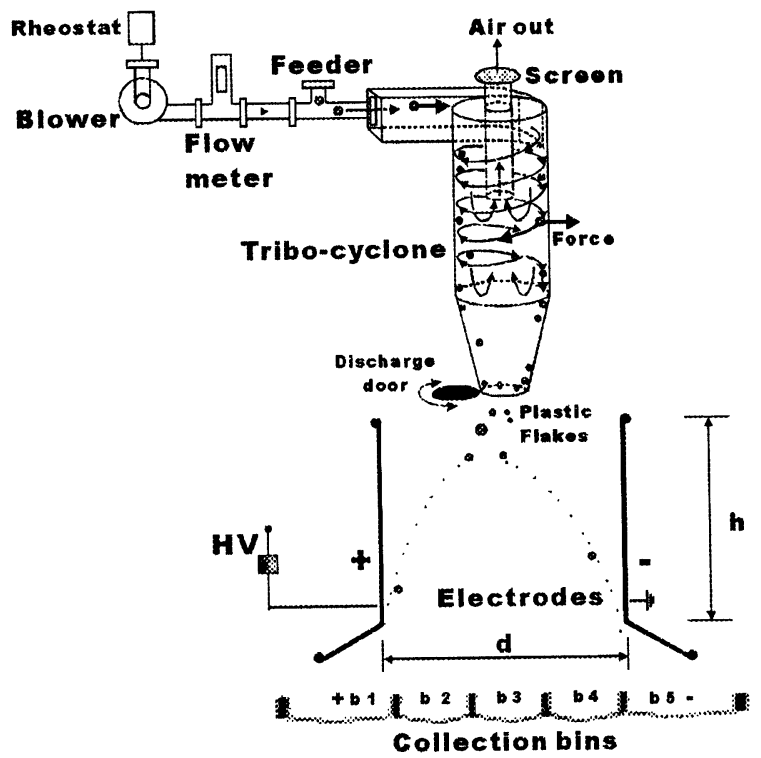

FIGURE 3 Schematic design of the laboratory-scale tribo-electrostatic separation system. 
The separation system consisted of six components: a blower, a feeder, a tribo-cyclone, a DC power source, a separating electrode system and five collection bins. The separating electrode system had two high voltage electrodes made of copper $(\mathrm{Cu})$. The electric field between the two electrodes was produced by a DC power source.

At first, the plastic feed was dispersed in a current of air provided by a blower and introduced into the tribo-cyclone through its tangential entry. The air-flow was regulated by a rheostat (TOSHIBA Voltslider Slidac S110) connected to the blower and measured by a flowmeter (Kanomax Anemomaster Model 24-6131). The air was used to transport the mixture in cyclone and to charge frictionally the plastic flakes against inner wall of the cyclone. A 20 mesh $(0.84 \mathrm{~m} / \mathrm{m})$ screen was placed at the top of the cyclone to prevent any flakes from overflowing.

After a certain period of the charging time, the blower was switched off and the discharge door of the cyclone was opened. As the flakes dropped due to the gravity in the central area between the electrodes, they were deflected towards positive electrode or the negative one, depending upon their surface charge. The amount of the acquired charge was controlled by regulating the air inlet velocity, the tribocharging time, the air relative humidity and temperature. In addition, the amount of deflection was controlled by the potential applied to the electrodes.

The separated flakes were collected into five collection bins. The bin on one side, next to the positive electrode, collected the negatively charged flakes, while the opposite side bin, collected the positively charged flakes. Flakes that had insufficient charge for separation were collected in the central bins.

Figure 4 illustrates the configurations of the tribo-cyclone and the separating electrode system.

The tribo-cyclone was a device that utilised centrifugal force to charge the flakes as a result of their acceleration and friction against the inner wall. The cyclone constructed from acrylic material had a diameter of $0.075 \mathrm{~m}$, a cone height of $0.16 \mathrm{~m}$ and a $0.04 \mathrm{~m}$ diameter vortex finder at a depth of $0.095 \mathrm{~m}$ in the cyclone body.

The configuration of the separating electrode system consisted of a top parallel part (height $=0.25 \mathrm{~m}$ ) and a bottom inclined one. The electrodes of $0.15 \mathrm{~m}$ width were disposed $0.06 \mathrm{~m}$ apart from each 


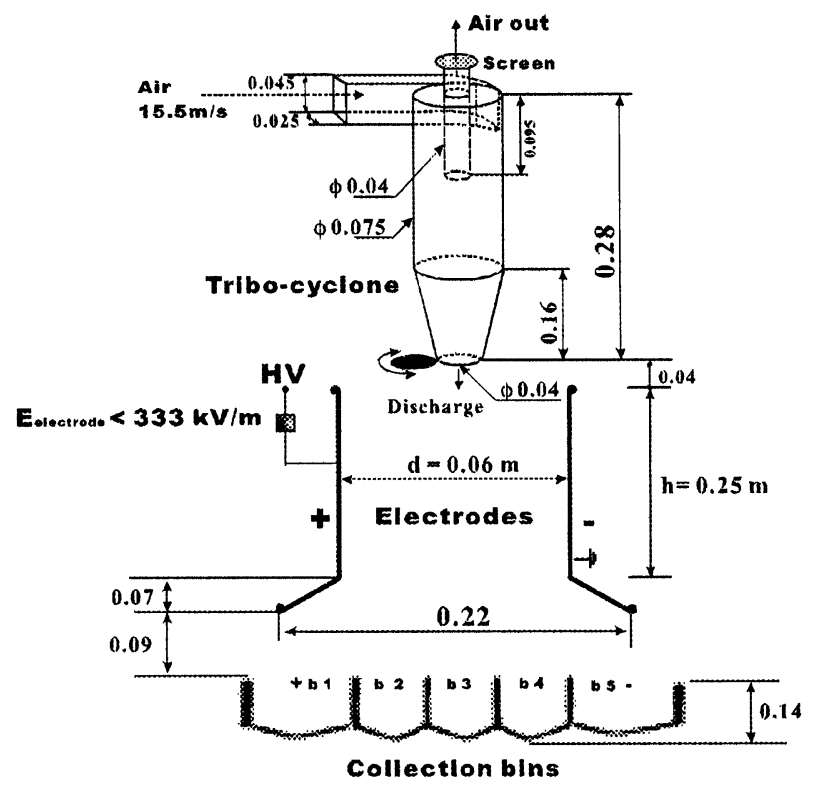

FIGURE 4 Configurations of the tribo-cyclone and the separating electrode system.

other. The DC power source applied up to $\pm 20 \mathrm{kV}$ to the electrodes, thus the maximum electric field of $333 \mathrm{kV} / \mathrm{m}$ was produced.

The collection bins (length $=0.24 \mathrm{~m}$, height $=0.14 \mathrm{~m}$ ) were located underneath the separating electrode system. The central bins named "b2", "b3" and "b4" had a width of $0.03 \mathrm{~m}$ respectively, whereas the side bins named "b1" and "b5" each had a width of $0.13 \mathrm{~m}$.

\subsection{Measurements of the Flake Surface Potential}

A non-contacting type electrostatic-voltmeter (TREK Model 523) was used to measure the surface potentials, $V_{s}$, of the polymer flakes (Fig. 2). The instrument was capable of measuring surface potentials from 0 to $\pm 20 \mathrm{kV}$. It should be noted that, the surface potential measurements were affected by changes in the distance $r$ between the detector of the instrument and the flake's surface. Therefore, only an average value of the surface potential from several measurements was reported in the results. The measurements were performed inside a temperature and humidity control chamber under controlled conditions. 


\subsection{Materials}

The experiments were carried out on $50 \% / 50 \%$ artificial mixtures of PET and PE (see Fig. 5). Plastic flakes of irregular shapes and approximately $1-3.5 \mathrm{~mm}$ in size were used throughout the experimental work. The difference in colour between plastic types allowed easy hand-sorting and analysis of the product streams. No special treatment of the materials, (such as chemical conditioning, etc.) was done prior to the experiments.

The experiments were performed in a "batch mode" of operation. During each run fresh samples from the same source were used and a batch size of approximately $3 \times 10^{-3} \mathrm{~kg}$ of plastic mixture was processed.

\subsection{The Density Measurements}

The density of each plastic component was measured by pycnometer and using ethanol (density $=789-791 \mathrm{~kg} / \mathrm{m}^{3}$ ) as the relative substance. The results of the measurements are tabulated in Table III.

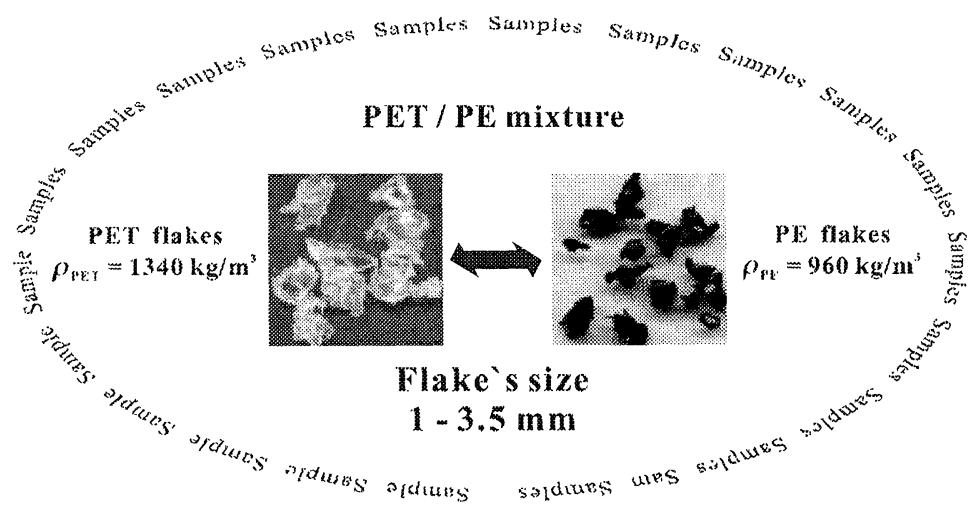

FIGURE 5 Components of the PET/PE artificial mixture.

TABLE III The density of plastic components of the PET/PE mixture

\begin{tabular}{lc}
\hline Polymer & Density, $\rho_{\text {sample }}\left[\mathrm{kg} / \mathrm{m}^{3}\right]$ \\
\hline PET & 1340 \\
PE & 960 \\
\hline
\end{tabular}




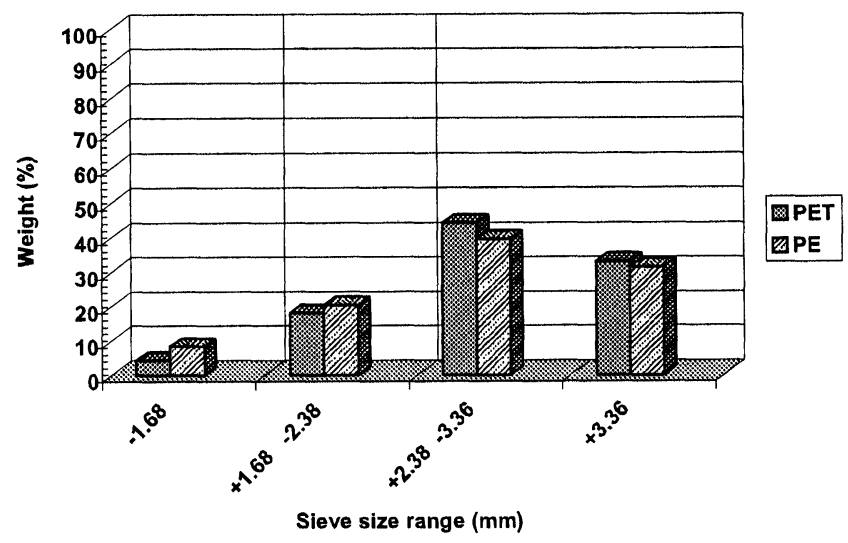

FIGURE 6 The fractional representation of screen analysis.

\subsection{The Particle Size Analysis}

In Fig. 6 the size distribution of the plastic components of the PET/ PE mixture is depicted. It can be seen that PET and PE exhibited similar distribution of flake size. Therefore, the characteristics of the plastics were considered more or less the same in terms of their mean diameter.

\subsection{The Contact Material for Tribo-Electrification}

Polystyrene (PS), the value of work function of which lies between the values of work function of PET and PE (Eq. 11; Table II) was used as the contact material (i.e. the inner wall of the cyclone for tribo-electrification of the PET/PE mixture. However, the acrylic was also tested.

$$
\phi_{\mathrm{PET}}=4.25 \mathrm{eV}<\phi_{\text {contact material }}<\phi_{\mathrm{PE}}=5.24 \mathrm{eV}
$$

\section{RESULTS AND DISCUSSION}

\subsection{Tribo-Electrification}

\subsubsection{The Effect of Temperature and Relative Humidity}

Subsequently, the variation of the surface potential $V_{s}$ with the air relative humidity $H$ and temperature $T$ for PET and PE was studied. 
The tests were performed inside the temperature and humidity control chamber (ESPEC type TBL-3HAOGAC) with the capability to vary the relative humidity between $10 \%$ and $90 \%$ and the temperature between $5^{\circ} \mathrm{C}$ and $35^{\circ} \mathrm{C}$.

During each run, the mixture was tribo-charged for 5 min against the inner wall of the cyclone made of PS material, maintaining the air inlet velocity at $15.5 \mathrm{~m} / \mathrm{s}$. The surface potential of each constituent in the mixture was measured at varying temperatures and relative humidity. More than 20 batches were tested, the experimental results were stored and processed in a computer.

The surface plots and contour maps of the variation in the surface potential as a function of temperature and relative humidity are shown in Fig. 7. These are three-dimensional representations of the experimental data that are displayed with the combination of "temperature", "relative humidity" and "surface potential", values. The contours define the lines of constant "surface potential" or, in other words, lines of constant elevation or value, across the extent of the map.

The observed data were interpolated as a polynomial regression and the regression coefficients were computed (Eqs. (12) and (13)).

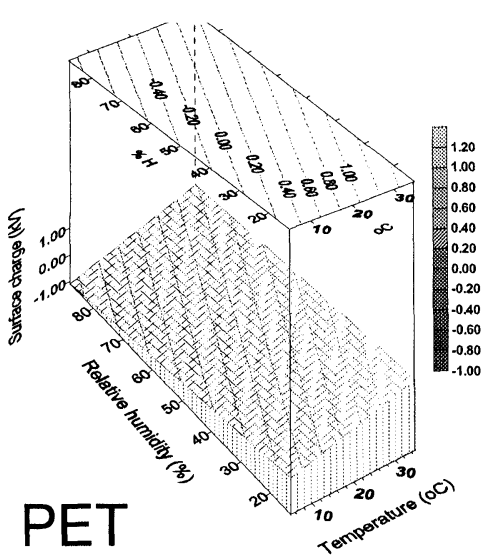

(a)

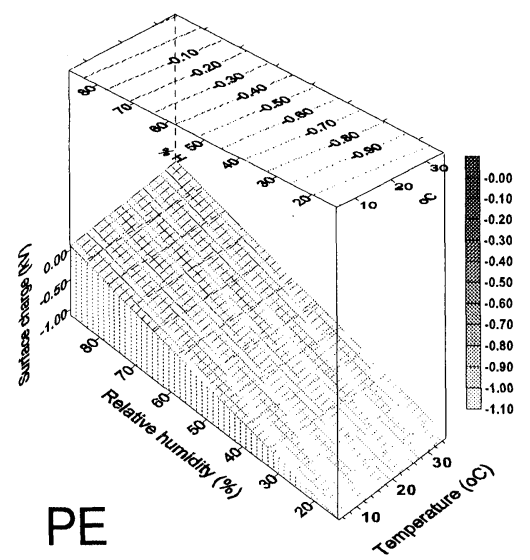

(b)

FIGURE 7 Variation of the surface potential $\left(V_{s}\right)$ with the air relative humidity $(H)$ and temperature ( $T$ ) for PET (a) and PE (b). 


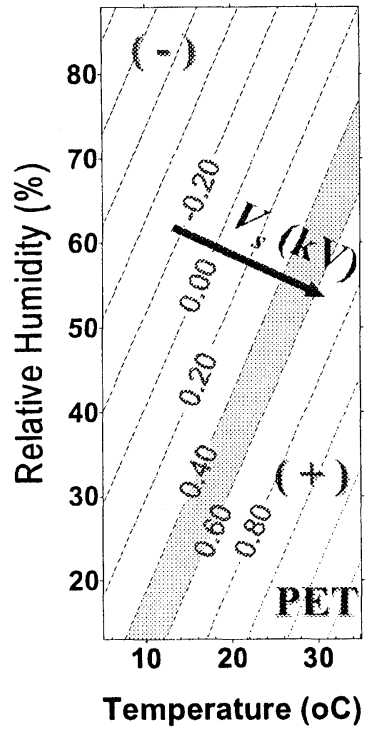

(a)

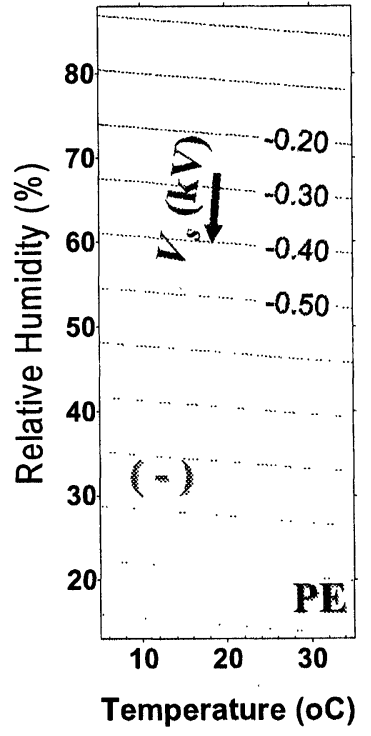

(b)

FIGURE 8 A contour map of the surface potential $\left(V_{s}\right)$ with air relative humidity $(H)$ and temperature (T) for PET (a) and PE (b).

The reproducibility of the results is excellent, as it was verified by repeating the measurements many times.

$$
\begin{aligned}
V_{s_{(\mathrm{PET})}} & =0.32-0.018 H+0.043 T \\
V_{s_{(\mathrm{PE})}} & =-1.35-0.015 H+0.001 T
\end{aligned}
$$

The results plotted in Fig. 8 confirm that the air relative humidity and the temperature affected the magnitude of the surface potential acquired by the polymers. Also the directions of the gradient vectors are plotted in Fig. 8. These are the gradients of the magnitude of the surface potential for each constituent of the PET/PE mixture. Moreover, in each contour map, the minimum level of the magnitude of the surface potential of PET (Fig. 8(a)) and PE (Fig. 8(b)) is shaded. This is the minimum required for electrostatic deflection of the flakes by the electric field of $333 \mathrm{kV} / \mathrm{m}$ and calculated by using Eq. (10). 
The effect of relative humidity and temperature appeared to be different for different polymers. It was observed that the polarity and magnitude of PET surface potential were influenced by the changes in relative humidity and temperature. Referring to Fig. 8(a), PET flakes acquired greater surface potential, when the relative humidity was decreased and the temperature was raised. Furthermore, the magnitude of the PE surface potential was increased especially when the relative humidity was decreased, as the variation of the temperature slightly effected it (Fig. 8(b)). Yet, when the humidity increased the magnitude of the surface potential of PE decreased but the polarity did not change.

These results proved that the changes in temperature $(T)$ and particularly in relative humidity $(H)$ have a pronounced influence on the surface potential of plastic components of this specific mixture.

In Fig. 9 the combined contour maps of constituents of the PET/PE mixture are plotted. It was found that the flakes should be mostly tribo-charged at dry ambient conditions in order to acquire a sufficient magnitude of the surface potential needed for their electrostatic

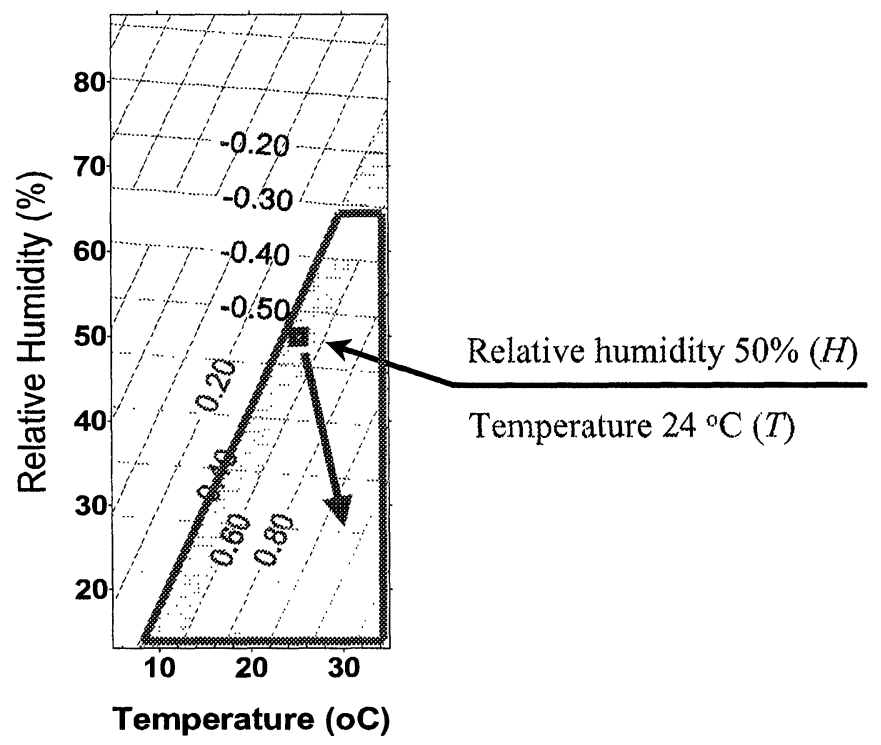

FIGURE 9 The combined contour maps of constituents of the PET/PE mixture. 
deflection towards the electrodes. Hence, taking into consideration the suggestions from the figures, the relative humidity of $50 \%$ and temperature of $24^{\circ} \mathrm{C}$ were selected as the standard levels for all subsequent experiments.

\subsubsection{The Effect of the Tribo-Charging Time}

The tribo-charging time had a great influence on the surface potential of the plastic flakes. Consequently, the PET/PE mixture was tribocharged for various times using an inner acrylic lined cyclone and the surface potential of each component was measured. During each run of the measurement, the air inlet velocity was maintained at $15.5 \mathrm{~m} / \mathrm{s}$. The measurements were performed inside the temperature and humidity control chamber. The temperature and the air relative humidity were fixed at $24^{\circ} \mathrm{C}$ and $50 \%$ respectively.

Figure 10 shows that the polarity of the transferred charge to the PET flakes changed from negative to positive exhibiting unclear tribo-charging tendency. This was probably due to the small work function difference between PET and Acrylic (Table II). However, it

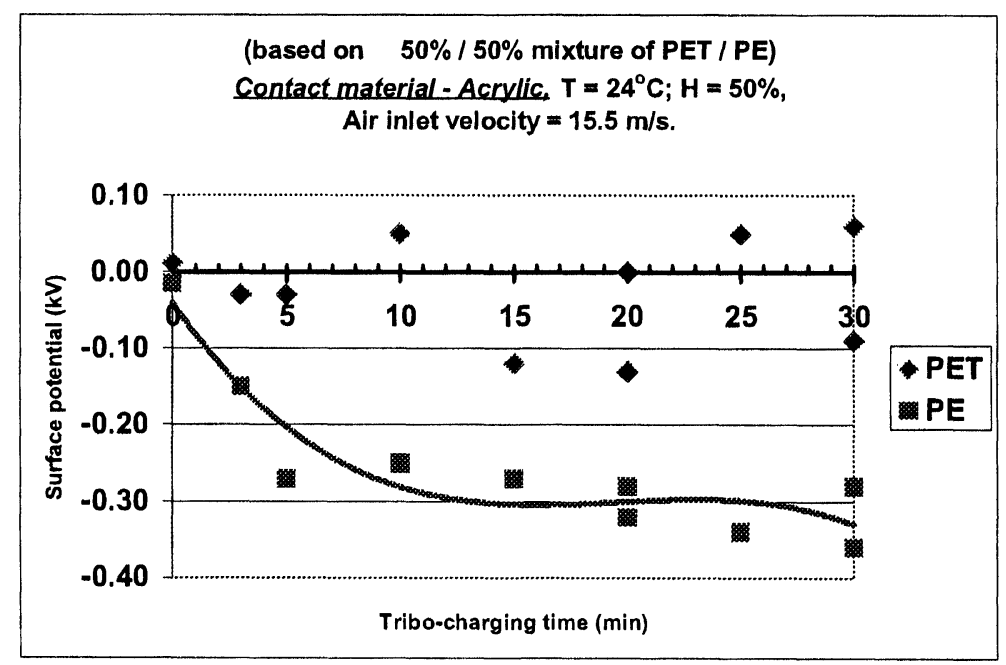

FIGURE 10 Effect of the tribo-charging time on the surface potential of the plastic flakes charged, using an acrylic lined cyclone. 


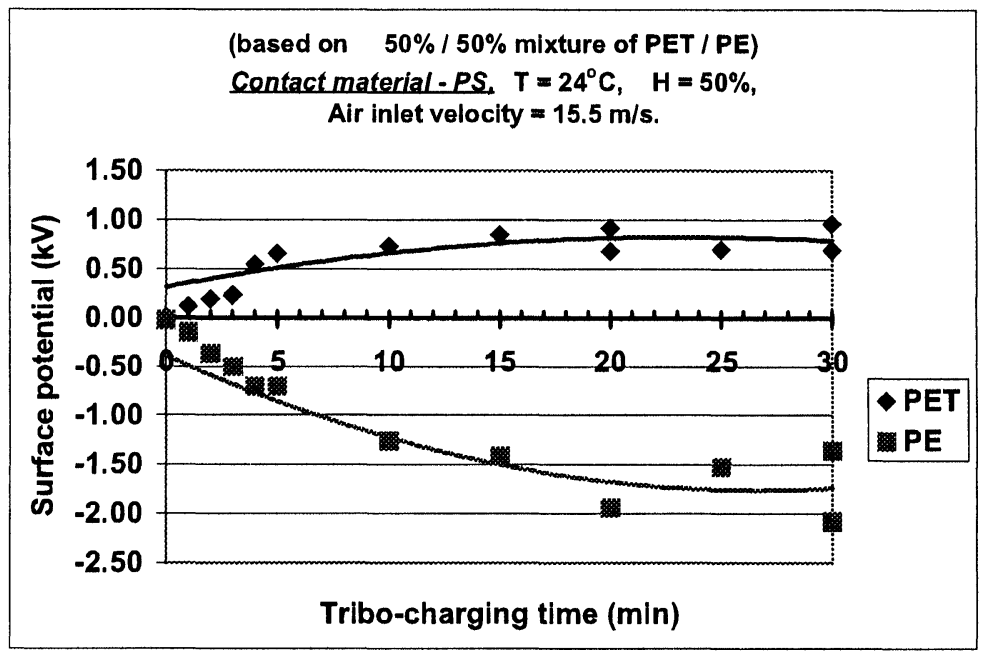

FIGURE 11 The effect of the tribo-charging time on the surface potential of the plastic flakes charged using a PS lined cyclone.

was clearly apparent that PE flakes manifested an increase of the magnitude of the surface potential, while the tribo-charging time was lengthened. Next, the measurements of the surface potential of each component of the PET/PE mixture were carried out under the same conditions as previously described with the exception of the fact that PS was used as a contact material for the frictional charging instead of acrylic.

The results (Fig. 11) have shown that PET flakes were charged positively after contacted with the PS medium, whereas PE flakes were charged negatively. These results were due to the fact that the work function of PS used as a contact material lies above that of PET but below that of PE (Eq. (14) Table II). As expected, the sign of the surface potential acquired by the flakes depended on the relative magnitude of the work functions of the flake surface and contact surface, respectively.

$$
\phi_{\mathrm{PET}}<\phi_{\mathrm{PS}}<\phi_{\mathrm{PE}}
$$

It was observed that for both components of the mixture, there is an increase of the magnitude of surface potential while the 
tribo-charging time is lengthened (Fig. 11). This was due to the increasing probability of friction between the plastic flakes and the inner wall of the cyclone.

Moreover, using Eq. (10), it was estimated that after $5 \mathrm{~min}$ of the frictional charging the components of the PET/PE mixture acquired a sufficient surface potential (Fig. 11). Thus a basis for their subsequent electrostatic separation under the electric field strength of $333 \mathrm{kV} / \mathrm{m}$ was provided.

Hence, taking into account the results of the measurements (Figs . 10 and 11), PS was chosen as a contact material for the tribo-electrification of PET/PE mixtures.

\subsubsection{The Effect of the Air Inlet Velocity}

Mongomery, reported in 1959 that there is an increase of the charge while the rubbing velocity was raised [32]. However, peaks have also been found [33]. Subsequently, the surface potential of each component of the PET/PE mixture and the plastic mass adhered to the cyclone were measured for various air inlet velocities. Batches were tribocharged separately for $5 \mathrm{~min}$ using a PS lined cyclone. The tests were conducted inside the humidity and temperature control chamber, while the temperature and the air relative humidity were fixed at $24^{\circ} \mathrm{C}$ and $50 \%$, respectively.

Figure 12 shows that an increase in the air inlet velocity increased the magnitude of the surface potential acquired by the flakes. This was due to the fact that the frictional charging between flakes themselves and the flakes against the cyclone's inner wall improved. It was evaluated that, when the air inlet velocity was maintained at $15.5 \mathrm{~m} / \mathrm{s}$ or greater, the components of the PET/PE mixture acquired a sufficient charge for their subsequent electrostatic separation under the electric field strength of $333 \mathrm{kV} / \mathrm{m}$. However, the upper limit of the air inlet velocity should be set because of static adhesion. Nevertheless, the mass of the flakes adhered to the cyclone grew sharply with the increase of the air inlet velocity (Fig. 13). Up to $5.1 \%$ of the feed adhered to the cyclone, while the air inlet velocity was maintained at $15.5 \mathrm{~m} / \mathrm{s}$. Considering the results (Figs. 12 and 13), the air inlet velocity of $15.5 \mathrm{~m} / \mathrm{s}$ was selected as the appropriate level for all subsequent experiments. 


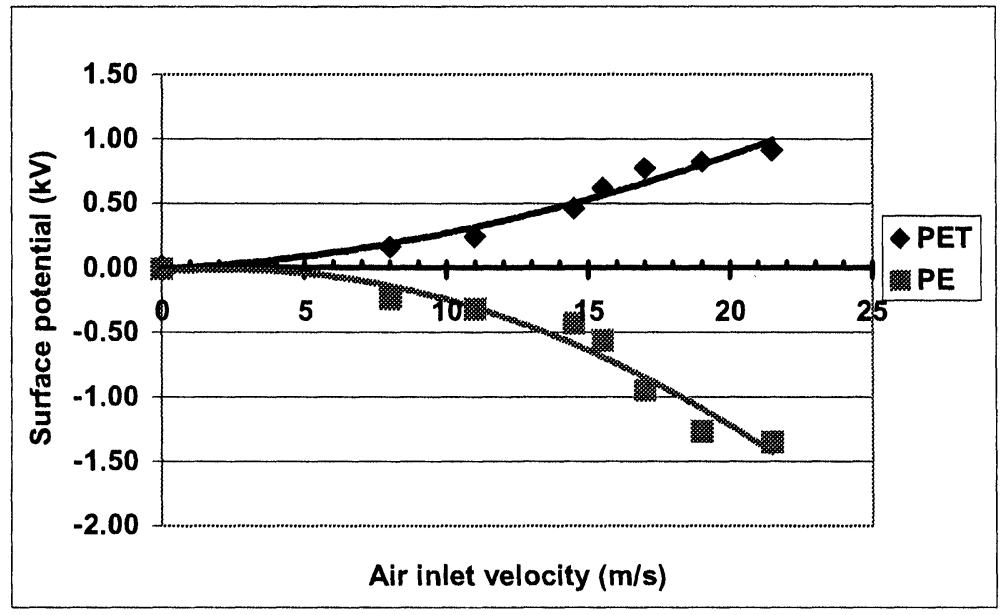

FIGURE 12 The effect of the air inlet velocity on the surface potential of the plastic flakes.

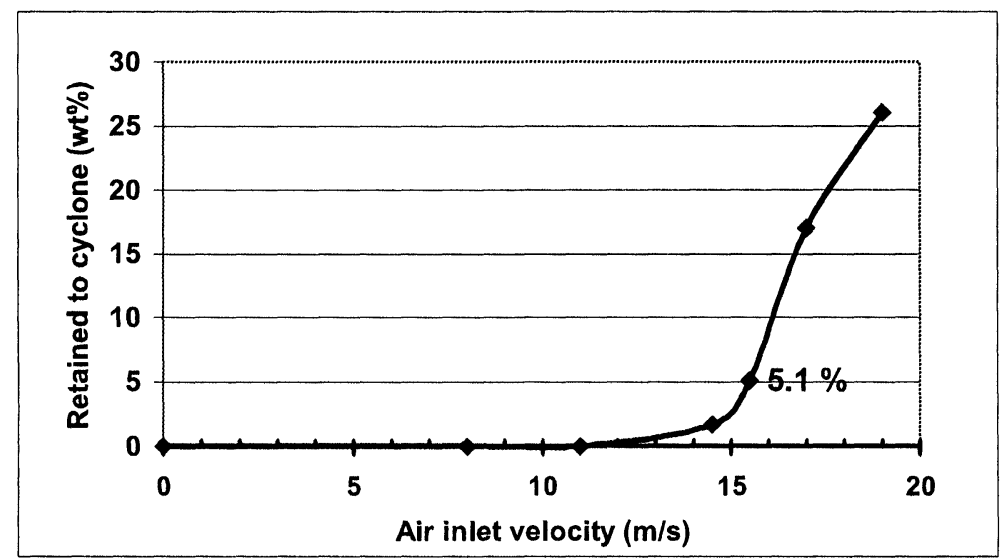

FIGURE 13 Mass of the material adhered to the cyclone as a function of the air inlet velocity.

\subsubsection{Examination of the Inner Lining Surface of the Cyclone}

Some problems were encountered due to collisions between the flakes and the inner wall of the cyclone. This in turn resulted in alteration of the inner-lining surface. The tribo-electrostatic charge acquired by 
the flakes depended on the parameter of roughness of the contact material. Therefore, representative samples of the PS inner lining were examined using scanning electron microscopy (SEM) and an instrument for texture measurements. The texture measurements were conducted by diamond styles (Rank Taylor Hobson, Form Talysurf Series) of a $2 \mu \mathrm{m}$ tip radius. The stylus force over the full range and the sliding velocity were $98 \cdot 10^{-4} \mathrm{~N}$ and $1 \mathrm{~mm}-\mathrm{sec}^{-1}$, respectively.

The profiles of the examined samples throughout the assessment length, parameter of roughness $R a$ and scanning photographs, before and after frictional charging are shown in Figs. 14-17. It is important to note that $R a$ is the universally recognized, and the most frequently used, international parameter of roughness. It is

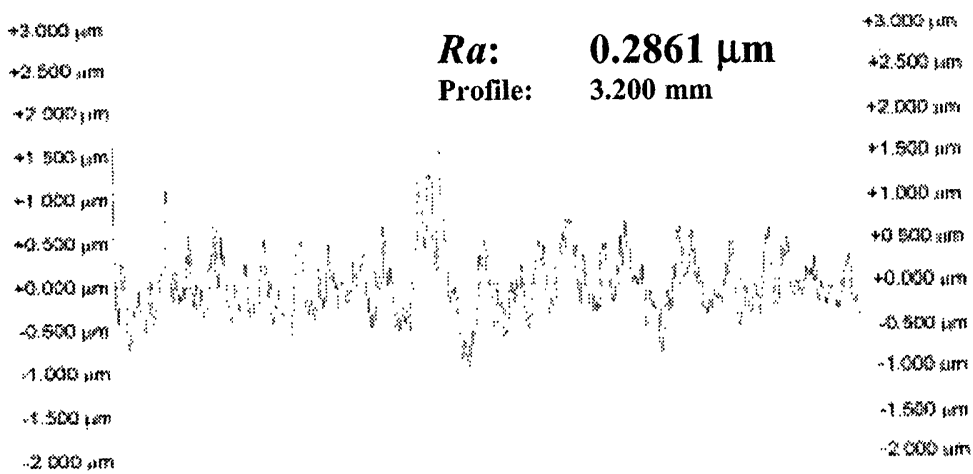

FIGURE 14 A profile of the PS inner lining before tribo-charging.

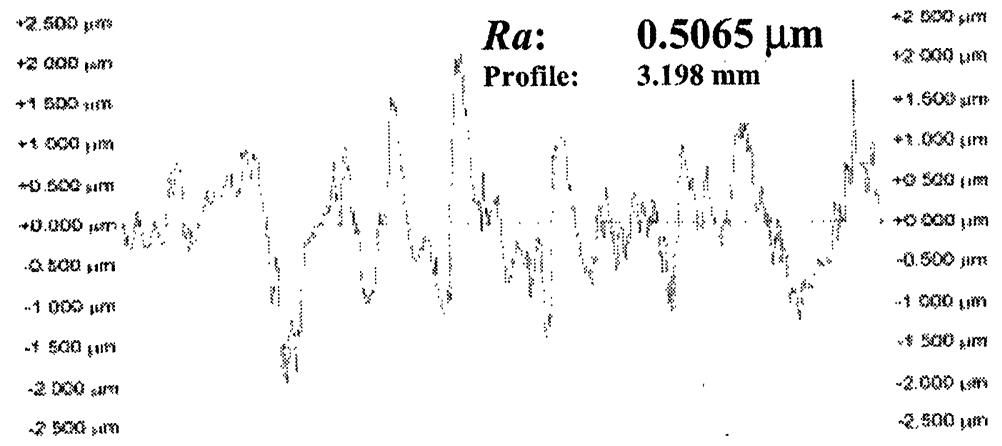

FIGURE 15 A profile of the PS inner lining after many tribo-charging tests. 


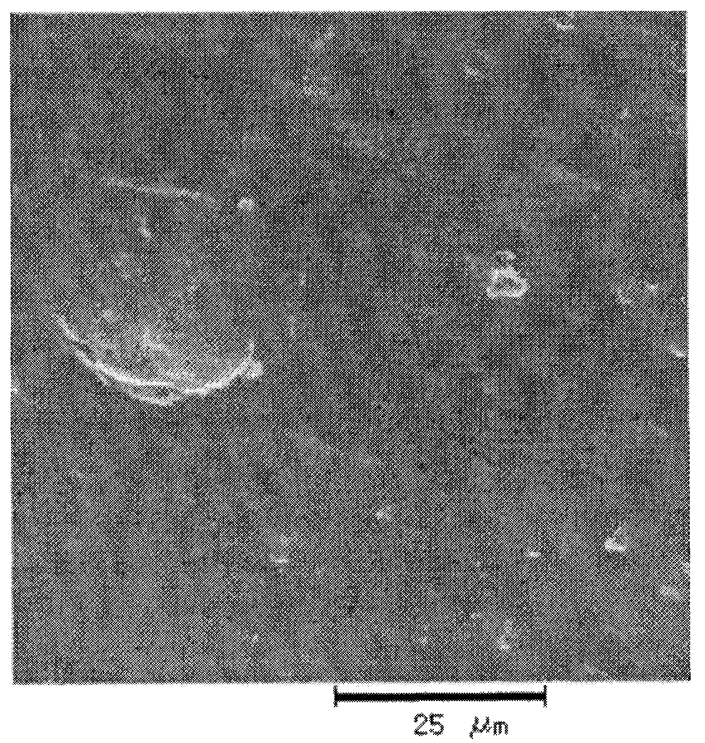

FIGURE 16 SEM photograph of the PS inner lining before tribo-charging.

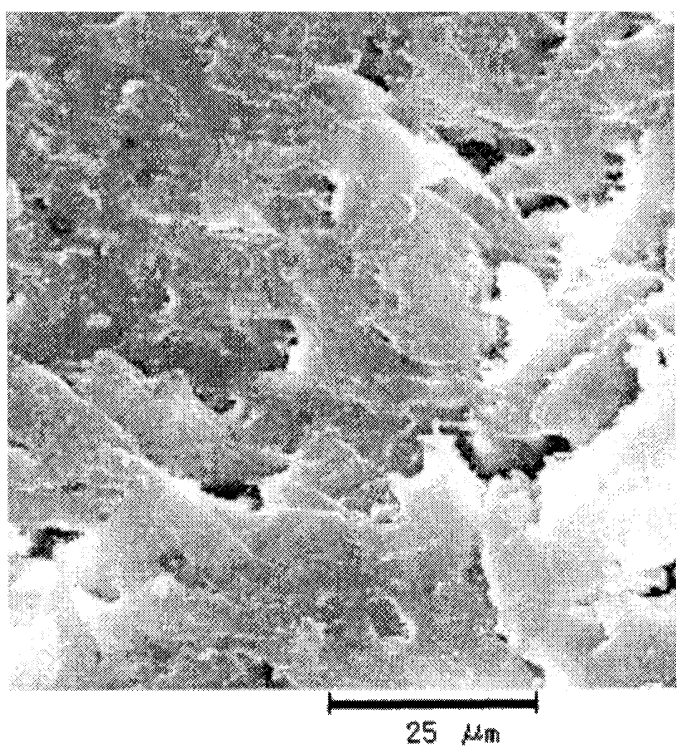

FIGURE 17 SEM photograph of the PS inner lining after many tribo-charging tests. 
the arithmetic mean of the departures of the profile from the mean line (Eq. (15)).

$$
R a=\frac{1}{L} \int_{0}^{L}|z(x)| d x
$$

It was clearly apparent that there was a change in the surface roughness after a series of tribo-charging tests. Referring to texture measurements, before tribo-charging process, the parameter of roughness $R a$ was $0.29 \mu \mathrm{m}$ (Fig. 14) and after many tests it became $0.51 \mu \mathrm{m}$ (Fig. 15).

Thus, as a result of the friction of plastic flakes against the cyclone's wall, the surface of the inner lining was damaged and its roughness was increased. This in turn caused that after a series of tests the flakes could not acquire sufficient tribo-charge due to a smaller area of contact. Hence, the material for the cyclone's inner wall should be chosen, also, on the basis of parameter of roughness and resistance to abrasion.

\subsection{Tribo-Electrostatic Separation}

\subsubsection{Typical Tribo-Electrostatic Collection and Separation Results}

Except where noted otherwise, prior to all subsequent electrostatic separation tests, PET/PE mixture was tribo-charged for $5 \mathrm{~min}$ using an inner PS lining cyclone, while the air entered in cyclone at velocity of $15.5 \mathrm{~m} / \mathrm{s}$. The air relative humidity and temperature were fixed at $50 \%$ and $24^{\circ} \mathrm{C}$, respectively. Following that, the mixture was passed through the electrostatic field of $333 \mathrm{kV} / \mathrm{m}$. At the end of each experiment, the individual separated fractions were collected and weighted. Then, the effectiveness of the separation of the two-component (A and B) mixture was measured in terms of grade (\%), recovery $(\%)$ and mass $(w t \%)$. These terms were defined as follows, where $A$ denoted one of the components of the mixtures.

$$
\text { Grade }_{A}=\frac{\text { Mass of material } A \text { in the collected fraction }}{\text { Total Mass of the collected fraction }} \cdot 100[\%]
$$




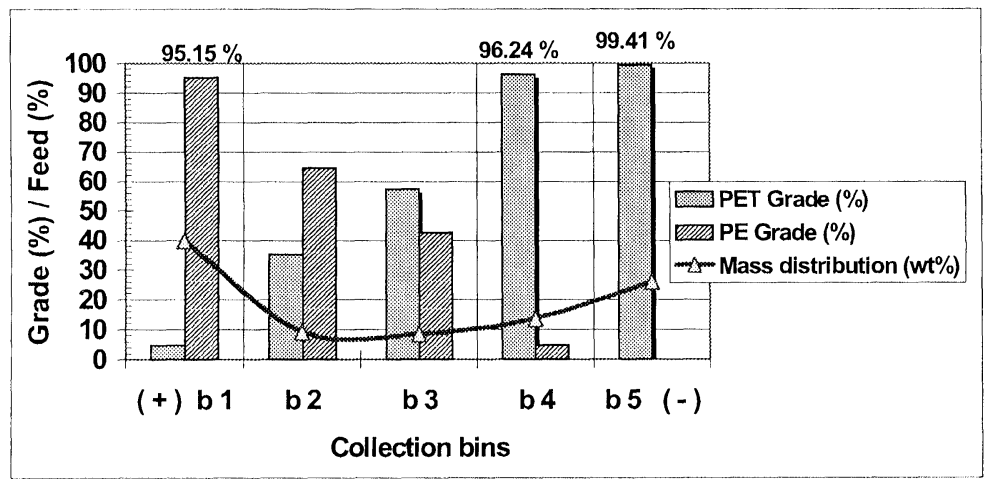

FIGURE 18 Typical grade in five collection bins for 50\%/50\% mixture of PET/PE.

Recovery $_{A}=\frac{\text { Mass of material } A \text { in the collected fraction }}{\text { Total mass of material } A \text { in feed stream }} \cdot 100 \quad[\%]$

$\mathrm{wt} \%=\frac{\text { Total mass of the collected fraction }}{\text { Total mass of batch being processed }} \cdot 100 \quad[\%]$

Furthermore, a typical collection for PET/PE mixture is presented. Fig. 18 shows that bin "b5" collected $99.41 \%$ PET, whereas bin "b1" collected $95.15 \%$ PE material. In the central bins "b2" and "b3" the grade of the collected components decreased.

The recoveries of each component in the five collection bins as well as the material adhered to the cyclone due to the frictional charging are graphically illustrated in Fig. 19. The percentage mass distribution among the bins is also shown. It can be seen that the percentage of the mass collected in central bins named "b2" and "b3" is much smaller than the one collected in the side bins, thus indicating that the components of the PET/PE mixture exhibited good separations.

It is observed that PE was collected mostly in a bin named "b1" next to the positive electrode, whereas PET was collected in bins " $b 4$ " and "b5", next to the negative electrode. This was due to the fact that the charge/mass ratio of PE is greater than the PET. Therefore, PE flakes exhibited easier deflection towards the negative electrode and were mostly collected in one bin; conversely, PET flakes, were collected in two bins, next to the positive electrode. 


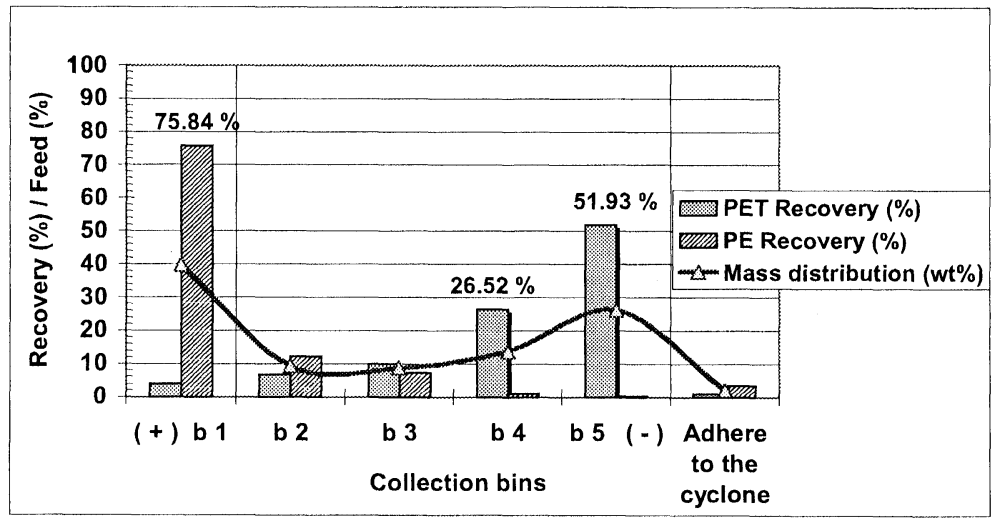

FIGURE 19 Typical recovery in five collection bins for 50\%/50\% mixture of PET/PE.

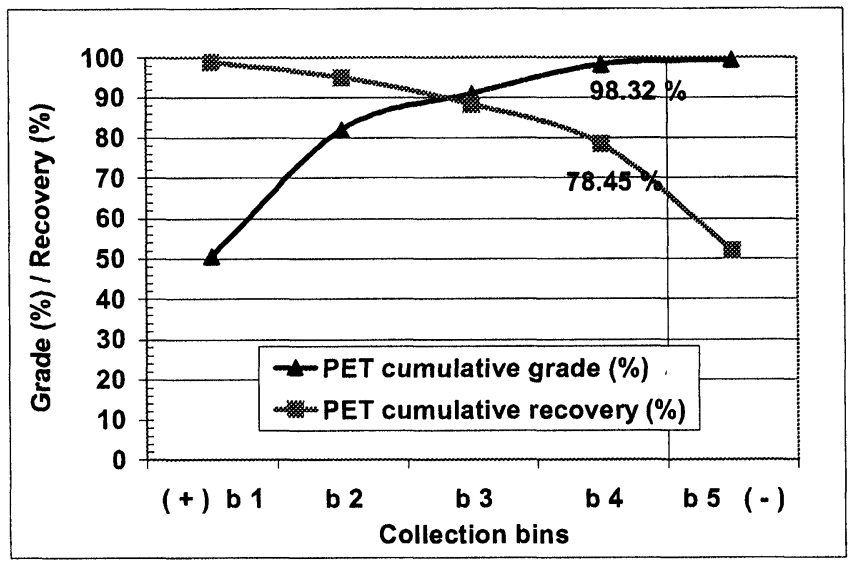

FIGURE 20 The separation results of PET.

On the other hand results of the typical collection are presented in terms of cumulative grade and cumulative recovery. Typical curves of the purification results for each constituent of the PET/PE mixture are plotted in Figs. 20 and 21.

Figure 20 shows that the choice of using only material collected in bins "b4" and "b5" gave the PET-grade of $98.32 \%$ and a recovery of $78.45 \%$. Conversely, the choice of using only material collected in bin "b1" gave the grade of $95.15 \%$ and a recovery of $75.84 \%$ of the PE component. 


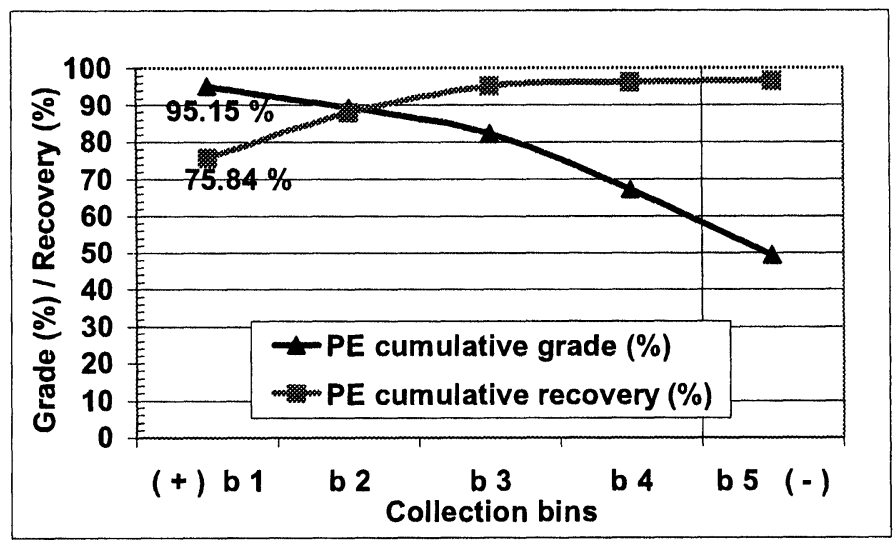

FIGURE 21 The separation results of PE.

\subsubsection{The Effect of the Electric Field Strength}

Two batches were tested separately. At first, they were tribo-charged under similar conditions fixing the air relative humidity and temperature at $50 \%$ and $24^{\circ} \mathrm{C}$, respectively. The air entered the PS lined cyclone at the velocity of $15.5 \mathrm{~m} / \mathrm{s}$ and tribo-charged the mixture for $5 \mathrm{~min}$. Subsequently, each batch was electrostatically separated under the electric field of 200 or $333 \mathrm{kV} / \mathrm{m}$.

Considering the results shown in Fig. 22, the PET grade and recovery improved when the electric field strength increased. Similar figures were obtained also for PE (Fig. 23). These results were due to easier deflection that the tribo-charged flakes exhibited in the separating electrode system under a greater electric field, as the electrostatic force acting on the flake was increased.

\subsubsection{Multi-Stage Processing}

In this case, two batches were tested independently from each other. Each of them was processed in a one-stage or a two-stage triboelectrostatic separation. Initially, the batches were tribo-charged for $4 \mathrm{~min}$ maintaining the air inlet velocity at $15.5 \mathrm{~m} / \mathrm{s}$. Then, the mixtures were passed separately through an electrostatic field of $333 \mathrm{kV} / \mathrm{m}$. Temperature and the relative humidity were fixed at $24^{\circ} \mathrm{C}$ and $50 \%$, respectively. 


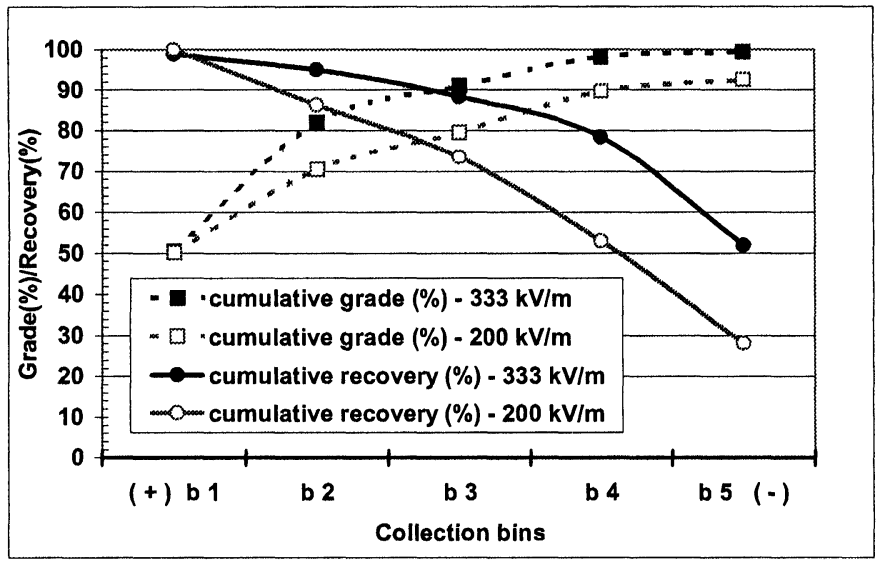

FIGURE 22 The effect of the electric field strength on the PET grade and recovery.

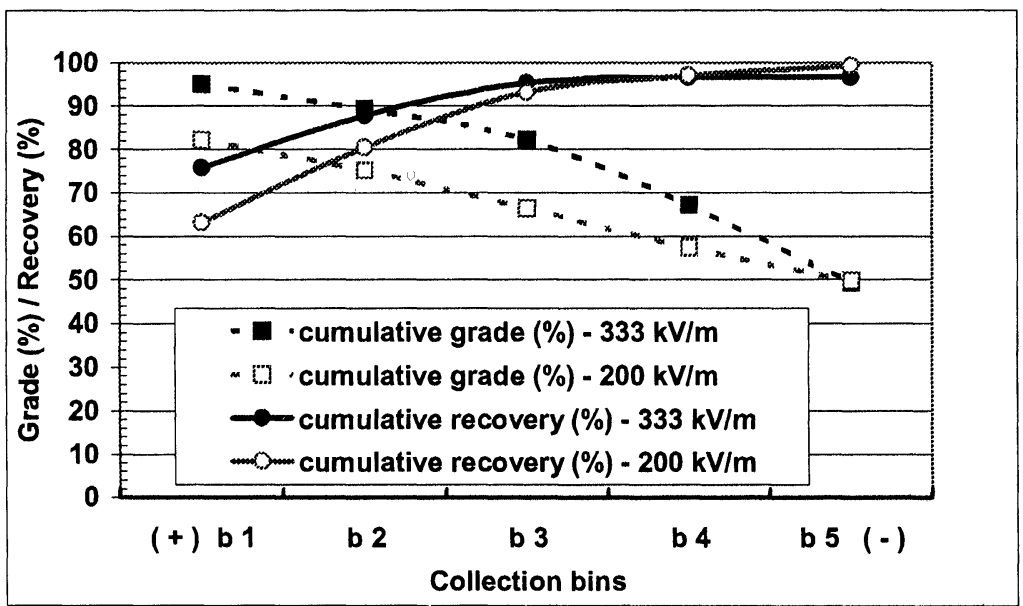

FIGURE 23 The effect of the electric field strength on the PE grade and recovery.

In the second-stage of separation only those fractions that were collected in the central bins named "b2", "b3" and "b4" are reprocessed. As expected by combining some of the fractions from the first stage of separation and then reprocessing these fractions using the second-stage of the process, the recovery of each component in the mixture was improved; however, the grade was slightly affected (Figs. 24 and 25). 
Referring to experimental results, the grades of $97.65 \%$ PET (Fig. 24) and $91.37 \%$ PE (Fig. 25), were obtained in the two-stage process while recoveries of $78.65 \%$ of PET (Fig. 24) and $88.27 \%$ of PE material (Fig. 25) were achieved.

Comparing the experimental results, it was observed that even though the mixture was tribo-charged for $4 \mathrm{~min}$ (rather than $5 \mathrm{~min}$ )

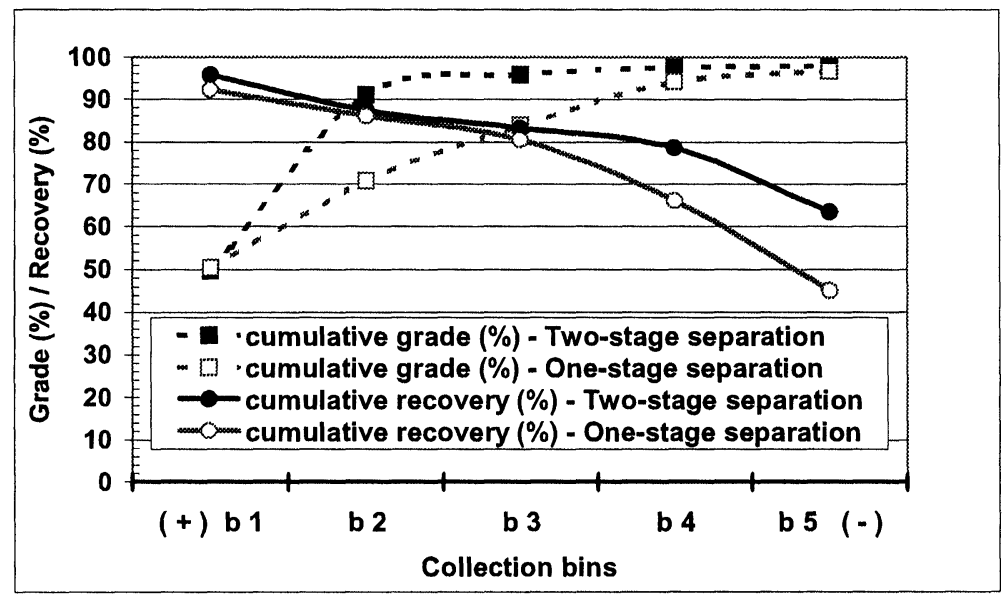

FIGURE 24 The effect of multi-stage separation on the PET grade and recovery.

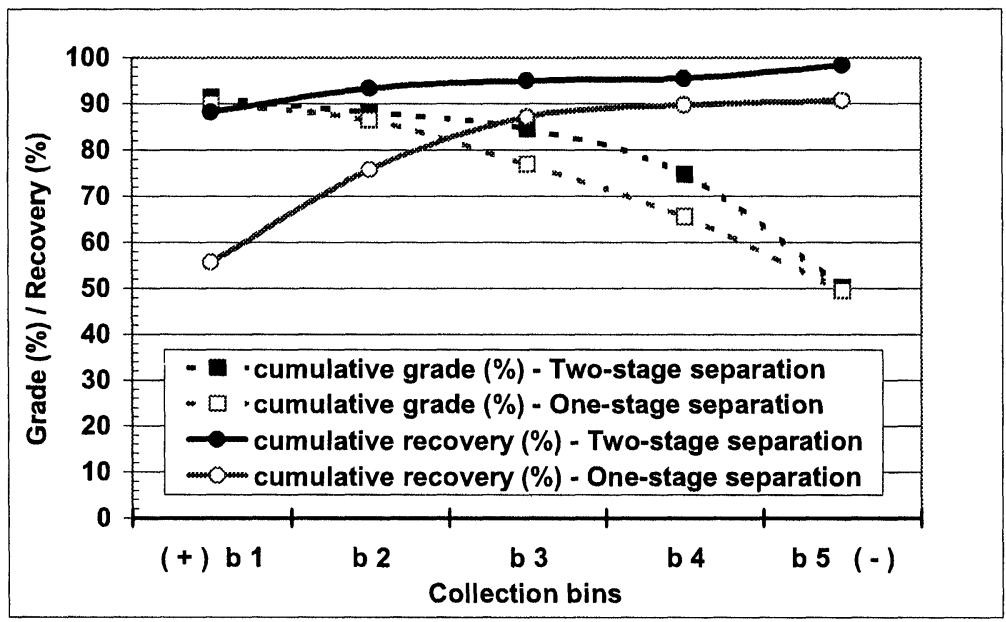

FIGURE 25 The effect of multi-stage separation on the PE grade and recovery. 
in the multi-stage processes, the grades and recoveries were similar to the case when the mixture was tribo-charged for $5 \mathrm{~min}$ and processed by single-stage tribo-electrostatic process only (Figs. 20, 21 and Figs. 24, 25). Hence, the results suggest that the multi-stage separation process can effectively reduce the duration the frictional charging or improve the recoveries of components of the mixtures.

\section{CONCLUSIONS}

1. The experimental study has proved an effective method, which consisted of:

(a) Tribo-electrification of shredded plastic mixture at controlled air relative humidity and temperature using a cyclone with a suitable inner wall material.

(b) Passing the electrified mixture between two high voltage electrodes.

2. The two-component artificial plastic mixtures of PET/PE were tribo-electrostatically separated in a one-stage process using a cyclone with inner PS lining. The grade of each plastic component in the mixture was greater than $95 \%$.

3. Tribo-electrification was strongly dependent on the surface potential of the components of the mixture. Therefore, controlling air relative humidity and temperature, the magnitude of the surface potential acquired by the plastic flakes increased.

4. Moreover, a suitable contact material and also an appropriate tribo-charging time and air inlet velocity improved frictional charging. This caused an increase of the transferred charge to the plastic flakes.

5. At last, the grade and the recovery of each polymer increased, while the electric field strength was increased and the mixture was separated in a two-stage process.

\section{LIST OF SYMBOLS}

$d \quad$ Distance between two electrodes [m]

D Diameter [m] 
$D_{\max } \quad$ Maximum diameter of the flake [m]

$E \quad$ Electric field strength between two electrodes [V/m]

$F \quad$ Electrostatic force [N]

$g \quad$ Acceleration due to gravity, $g=9.81\left[\mathrm{~m} / \mathrm{s}^{2}\right]$

$h \quad$ Height of electrode $[\mathrm{m}]$

$H \quad$ Air relative humidity [\%]

$k \quad$ Dimensionless coefficient found experimentally [-]

$L \quad$ Sampling length. This is the length of the reference line used to identify the surface roughness $[\mu \mathrm{m}]$

$m \quad$ Mass $[\mathrm{kg}]$

$Q \quad$ Charge [C]

$r \quad$ Distance between plastic flake and electrostatic voltmeter [m]

$R a \quad$ Parameter of roughness $[\mu \mathrm{m}]$

$T$ Temperature $\left[{ }^{\circ} \mathrm{C}\right]$

$V \quad$ Potential difference between two electrodes [V]

$V_{s} \quad$ Surface potential of the plastic flake [V]

$W \quad$ Gravitational force $[\mathrm{N}]$

$x \quad$ Space along the surface (X axis) $[\mu \mathrm{m}]$

$Z \quad$ Vertical displacement of the profile $(\mathrm{Z}$ axis) $[\mu \mathrm{m}]$

$\phi \quad$ Work function [eV]

$\varepsilon_{0} \quad$ Permittivity of free space $\varepsilon_{0}=8.854 \times 10^{-12}\left[\mathrm{C}^{2} / \mathrm{N} \mathrm{m}^{2}\right]$ $\left[\mathrm{C}^{2} / \mathrm{N} \mathrm{m}^{2}\right]$

$\varepsilon_{r} \quad$ Relative dielectric constant or permittivity ratio of the air $\varepsilon_{r}=1.0059[-]$

$\rho \quad$ Density $\left[\mathrm{kg} / \mathrm{m}^{3}\right]$

\section{Acknowledgements}

The authors gratefully acknowledge and gently appreciate Dr. Y. Akagami's very valuable technical support and advice.

\section{References}

[1] R.I. Stessel (1996). Recycling and Resource Recovery Engineering. pp. 1-21. Springer-Verlag, Berlin Heidelberg.

[2] The Environmental Agency in Japan (1999). "Kankyo Hakusho", The Finance Ministry, Printing in Japan, 148-149. 
[3] K. Saitoh, I. Nagano and S. Izumi (1976). New separation technique for waste plastics. Resource Recovery and Conservation, 2, 127-145.

[4] J. Shimoiizaka, A. Kounosu and Y. Hayashi (1974). Fundamental research on wet separation of waste plastics by combination of sink-float separation and flotation. J. of Mining and Metallurgical Inst. Japan, 90, 775-779 (in Japanese).

[5] A. Kounosu, Y. Hayashi and K. Saito (1978). Separation between polypropylene and polyethylene by means of flotation. J. of Mining and Metallurgical Inst. Japan, 94, 475-478. (in Japanese).

[6] J. Shibata, S. Matsumota, E. Kusaka, H. Yamamoto and Y. Morimoto (1996). Feasibility of flotation to separate waste material. Mining and Materials Processing Inst. Japan, 112, 177-184.

[7] J. Drelich, T. Payne, J.H. Kim and J.D. Miller (1998). Selective froth of PVC from PVC/PET mixtures for the plastics recycling industry. Polymer Engineering and Science, 38, 1378-1386.

[8] J. Shimoiizaka, A. Kounosu, U. Hayashi and K. Saito (1976). A new type sink-float separator for waste plastics. J. of Mining and Metallurgical Inst. Japan, 92, 675-679 (in Japanese).

[9] T. Fujita, N. Haruki, G. Dodbiba, P. Jing, T. Miyazaki and E. Kuzuno (2000). Various kinds of plastics and paper separation using electrostatic separation and the combination of sink-float separation and flotation for recycling. Proceedings of the XXI international mineral processing congress, Vol. B, pp. B12a-1-B12a-8. June 23-27, Rome, Italy.

[10] R. Ciccu, R. Peretti, A. Serci, M. Tamanini and A. Zucca (1989). Experimental study on triboelectric charging of mineral particles. Journal of Electrostatic, 23, $157-168$.

[11] R. Ciccu, M. Ghiani, P. Peretti, A. Serci and A. Zucca (2000). A new electrostatic separator for fine particles. Vol. A, pp. 42-51. Proceedings of the XXI International Mineral Processing Congress.

[12] I.I. Inculet, R.M. Quigley, M.A. Bergougnou and J.D. Brown (1980). Electrostatic beneficiation of Hat Creek coal in the fluidized bed state. CIM Bulletin, Oct., 51-61.

[13] X.K. Jiang, H. Ban, J.K. Neathery, T.X. Li and J.M. Stencel (1999). A new approach for removing talc for upgrading molybdenite ores. SME Annual meeting, March 1-3, Denver, Colorado, 1-4.

[14] S. Masuda, M. Toraguchi, T. Takeo and H. Haga (1983). Electrostatic beneficiation of coal using a cyclone-tribocharger. IEE Transactions on industry application. Vol. 1A-19, No. 5, Sep/Oct., 789-793.

[15] M.J. Pearse and M.I. Pope (1976). The separation of quartz-dolomite powders using a triboelectric technique. Powder Technology, 14, 7-15.

[16] M.J. Pearse and M.I. Pope (1977). The triboelectric separation of quartz-calcite and quartz-apatite powders after chemical conditioning. Powder Technology, 17, 83-89.

[17] T. Fujita, M. Imai, N. Haruki, B. Jeyadevan, M. Miyazaki and A. Bekkala (1999). Electrostatic separation of various kinds of plastics and papers, pp. 277-280. Proceedings of Fifth International Symposium on East Asian Recycling Technology, June 15-17, Tsukuba, Japan.

[18] S. Arai, S. Ito, E. Oi, H. Yotsumoto, E. Kikuchi and H. Sakamoto (1995). Study of the dry separation of plastics using a column-type air separator. Proceedings of the Annual Meeting of MIMIJ, 110 (in Japanese).

[19] Y. Matsushita, N. Mori and T. Sometani (1999). Electrostatic separation of plastics by friction mixer with rotary drum blades. Electrical engineering in Japan, 127(3), 33-40.

[20] I.I. Inculet and G.S.P. Castle (1991). Tribo-electrification of commercial plastic in air. Inst. Phys. Conf. Ser. No. 118: Section 4, paper presented at Electrostatics '91, 217-222. 
[21] T. Fujita, Y. Kamiya, N. Shimizu and T. Tanaka (1995). Basic study of polymer particles separation using vibrating feeder and electrostatic high voltage generator, pp. 155-164. Proceedings of the third International Symposium on East Asian resources Recycling Technology, November.

[22] Y. Higashiyama and K. Asano (1998). Recent progress in electrostatic separation technology. Particulate Science and Technology, 16, 77-90.

[23] I.I. Inculet, G.S.P. Castle and J.D. Brown (1992). Electrostatic separation of mixed plastic waste, pp. 10/1-1-1-13. Proceedings Davos Recycle '92, Davos Switzerland.

[24] B.A. Kwetkus and K. Sattler (1991). Contact charging of oxidized metal powders. Z. Phys. B-Condensed Matter, 82, 87-93.

[25] B.A. Kwetkus and K. Sattler (1992). Analysis of repeated-contact electrification curves. J. Phys. D. Appl. Phys., 25, 1400-1408.

[26] B.A. Kwetkus (1998). Particle triboelectrification and its use in the electrostatic separation process. Particulate Science and Technology, 16, 55-68.

[27] F.A. Vick (1953). Theory of contact electrification. Brit. J. Appl. Phys., Suppl. No. 2, S1-S5.

[28] W.D. Greason and I.I. Inculet (1975). Insulator work function from contact charging with metals. IEEE-IAS Annual Conf. Proceedings, 18B, 428-435.

[29] R. Gupta, D. Gidaspow and D.T. Wsan (1993). Electrostatic separation of powder mixtures based on the work function of its constituents. Powder Technology, 75, 79-87.

[30] I.I. Inculet, G.S.P. Castle and J.D. Brown (1994). Tribo-electrification system for electrostatic separation of plastics. IEE-IAS Annual Conf. Proceedings, 1397-1399.

[31] D.K. Davies (1969). Charge generation on dielectric surfaces. Brit. J. Appl. Phys. (J. Phys. D), Appl. Phys. Ser. 2, 2, 1533-1537.

[32] D.J. Mongomery (1959). Static electrification of solids. Solid State Phys., 9, 139-196. Academic, New York.

[33] K. Ohara (1979). Contribution of molecular motion of polymers to frictional electrification. Inst. Phys. Conf. Ser. No. 48, 257-264.

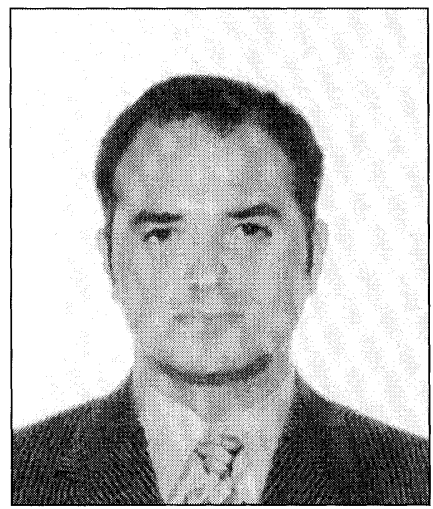

Gjergj A. Dodbiba was born in 1970 and in 1994 he graduated from the Polytechnic University of Tirana, Albania. In 2001 he obtained his master degree in Mineral Engineering from the Graduate School of Mining and Engineering, Akita University, Japan. He is currently studying for his $\mathrm{PhD}$ degree in Mineral Processing at Akita University. His $\mathrm{PhD}$ involves the study of tribo-electrostatic separation of several mixtures. 